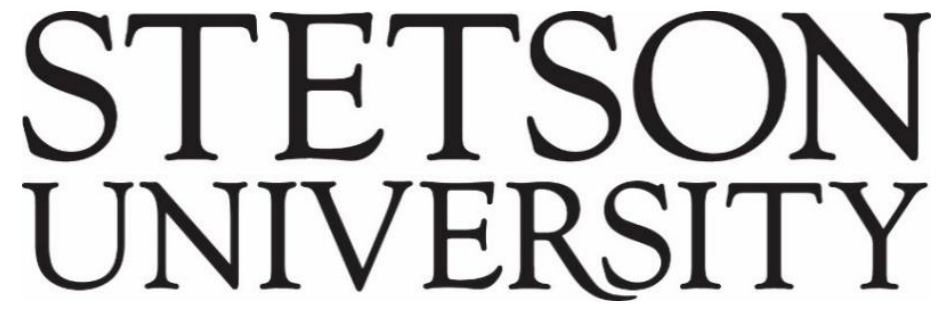

Voices of Reform: Educational Research to Inform and Reform

Volume 3 - Issue 1 - Article 3

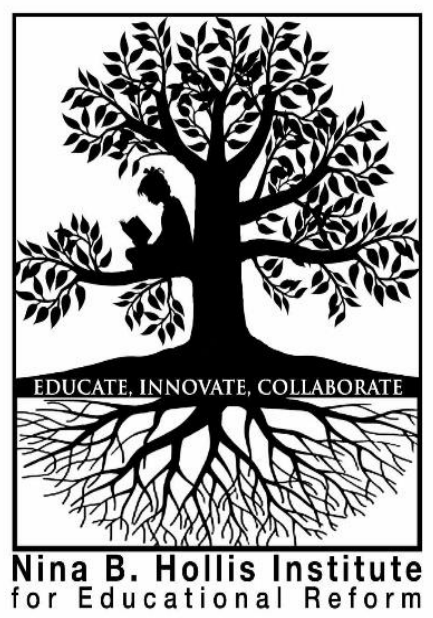

May 2020

\title{
Ties That Bind: Knowledge Movement and Tie Formation in a Regional Principals' Learning Network
}

Jennifer R. Karnopp

Indiana University

Follow this and additional works at: http://www.voicesofreform.com

Recommended Citation

Karnopp, J. (2020). Ties that bind: Knowledge movement and tie formation in a regional principals' learning network. Voices of Reform, 3(1), 55-76. Retrieved from https://www.voicesofreform.com/article/12772-ties-thatbind-knowledge-movement-and-tie-formation-in-a-regional-principals-learning-network doi: 10.32623/3.00005

http://dx.doi.org/10.32623/3.00005

Revisions

Submission date: July $12^{\text {th }}, 2019$

$1^{\text {st }}$ Revision: August 19 ${ }^{\text {th }}, 2019$

Acceptance: August 21 ${ }^{\text {st }}, 2019$

Publication date: May $1^{\text {st }}, 2020$ 


\title{
Ties that bind: Knowledge movement and tie formation in a regional principals' learning network
}

\author{
Jennifer Karnopp ${ }^{1}$ \\ ${ }^{1}$ Department of Education Leadership and Policy \\ Indiana University, United States \\ jkarnopp@indiana.edu
}

\begin{abstract}
Regional professional learning networks support school change by linking principals to others engaged in similar change work. While increasingly prevalent, little is known about the factors that contribute to the formation of ties between network members, or how knowledge moves across the network. Using social network analysis, this study examined the flow of information and advice in one such network and uncovered school leader and school characteristics correlated with increased tie strength, including being in the same state, having different years of network membership, and to a lesser extent, serving similar grade levels.
\end{abstract}

\section{Keywords}

social network analysis, program assessment, educational leadership

\section{Introduction}

Regional professional learning networks - sometimes called networks for learning — are voluntary educational support systems designed to support a specific school change goal by providing information, resources and opportunities for members to connect with one another. An external organization typically serves as central "hub" and a variety of different schools, often spanning district boundaries, serve as "outlets". The hub provides resources, as well as communication and organizational structures that allow members to connect with the hub and one another (Glazer \& Peurach, 2012; LeMahiew, Grunow, Baker, Nordstrum \& Gomez, 2017; Peurach \& Gumus, 2011). Through these structures, members support one another and share resources and experiences relating to the specific change goal (Glazer \& Peurach, 2012; LeMahiew, et al., 2017).

Support from large foundations, including the Carnegie Foundation for the Advancement of Teaching and the Bill and Melinda Gates Foundation, has spurred interest in regional professional 
learning networks in the U.S. A strong theoretical literature base supports the underlying structures and processes utilized by these multi-site networks (Bryk, Gomez \& Grunow, 2010; Bryk, Gomez, Grunow \& LeMahieu, 2015; Glazer \& Peurach, 2012; Peurach \& Glazer, 2012; Peurach, Glazer \& Lenhoff, 2016). Recently, some researchers have explored the formation of network leadership teams, or "hubs" (Proger, Bhatt, Cirks, \& Gurke, 2017; Russell, Bryk, Dolle, Gomez, LeMahieu, Grunow, 2018). However, empirical research on the functioning and effectiveness of these regional learning networks is sparse, and how knowledge flows among members remains unexplored. As more of these networks emerge across the country, there is a need for research aimed at understanding their potential for supporting school leaders in achieving desired change goals.

This article addresses this need by examining the frequency of interactions relating to the exchange of information and advice among school principals affiliated with a regional professional learning network that crosses district and state boundaries. Utilizing the lenses of organizational learning (Argyris \& Shön, 1978) and diffusion (Rogers, 2003) theories, which attend to how information sharing supports organizational change, I employed social network analysis (Wasserman \& Faust, 1994) to understand how principals' interactions support the movement of information among members working to achieve organizational change.

\section{Review of the Literature}

\section{School Change and the Role of the Principal}

School leaders play a variety of critical roles in the implementation of school-wide change efforts, including mediating new initiatives through the allocation of resources, and framing the messaging teachers receive about the initiative (Coburn \& Russell, 2008; Levin \& Fullan, 2008). School leaders also support the success of change efforts when they work to encourage a philosophical alignment with teachers relating to the desired change (Brezicha, Bergmark \& Mitra, 2015; Fullan, 2011). In a study of a district network's ability to support research use in schools, Finnigan and colleagues found that school leaders played a critical role in bridging district goals and teacher understanding (Finnigan, Daly \& Che, 2013). This research highlights the importance of the principal's social network for developing knowledge that supports organizational goals, suggesting that school leaders serve as "information brokers," bridging their schools with innovative ideas stemming from the network, and buffering the school from ideas less relevant to the local context (Daly, Finnigan, Moolenaar \& Che, 2014; Frank, Zhao, Penuel, Ellefson \& Porter, 2011). These findings suggest that it is particularly important to have school leaders "plugged in" to information networks by engaging in social interactions around district change efforts.

\section{Social Interactions and School Change}

Research examining changes in educator practice in the context of reform implementation identifies two critical elements related to a school's capacity for change-educator access to information about the desired change and opportunities to interact with other educators in ways that challenge prior assumptions and refine understandings of the change idea (Brezicha, Bergmark \& Mitra, 2015; Spillane, 1999; Coburn, 2001; Penuel, Riel, Joshi, Pearlman, Kim \& Frank, 2010; Yoon, Koehler, Yom, Yang \& Liu, 2017). Social interactions are a means of providing both access 
to information and opportunities to interact. Such social interactions help educators to make sense of the new initiative and positively impact changes in classroom teaching practices (Coburn, 2005; Coburn, Mata \& Choi, 2013; Spillane, 1999; Spillane, Reiser \& Reimer, 2002). Over the past decade researchers have further enhanced our understandings of the value of social interactions for achieving change in teaching practices by utilizing social network analysis as a methodology for examining interactions among educators in schools undergoing change implementation (Coburn, Mata \& Choi, 2013; Daly, Moolenaar, Bolivar \& Burke, 2010; Finnigan, Daly \& Che, 2013; Frank, Penuel \& Krause, 2015; Frank, et al., 2011; Liou \& Daly, 2016; Moolenaar, Sleegers, Karsten, Sjoerd \& Daly, 2012).

Evidence suggests that a school's policy context-particularly social policy (Coburn, Mata \& Choi, 2013) and organizational structures (Spillane, Hopkins \& Sweet, 2015)—contribute to the formation of social ties, or interactions between individuals, within and across schools. Opportunities for interaction appear to be critical to the formation of ties that lead to both information access and exchanges relating to teaching practices (Penuel, et al., 2010). For example, in their study examining staff interactions relating to instruction within and across schools in two districts, Spillane and colleagues (2015) found that there was some evidence of a correlation between similarity of school site characteristics (such as having a similar proportion of students of a particular socio-economic background) and the formation ties between individual educators. However, the majority of studies exploring educator interactions and changes in teaching practices examine the substance and frequency of these interactions among individuals within the same school or district (e.g., Brezicha, Bergmark \& Mitra, 2015; Coburn, Mata \& Choi, 2013). We know little about the factors that may lead to the development of ties between individuals who do not share the same organizational context (i.e. do not work in the same school or the same district), as is common in regional professional learning networks.

\section{Regional Professional Learning Networks}

Formal regional professional learning networks focus on providing their members with access to information and opportunities to interact with other members from different schools and districts (Barletta, Comes, Perkal, Shumaker, Wallenstein, and Yang, 2018). The network "hub", or leadership team, promotes structures and routines designed to gather and share information (Barletta, et al., 2018; Bryk, Gomez \& Grunow, 2011; Leithwood \& Azah, 2016; Peurach \& Glazer, 2012; Proger et al., 2017; Russell, et al., 2018). These structures facilitate the movement of information and advice across the network and allow the hub to gather and build knowledge, which is then disseminated among network members. Hubs also facilitate opportunities and spaces for collaborative work among members (Barletta, et al., 2018; Peurach, 2016; Proger et al., 2017). As such, participation in these networks provides educators with both access to information about the desired change and opportunities to interact with other educators, and therefore have the potential to positively impact school change efforts. The extent to which members take advantage of these opportunities and exchange information and ideas has yet to be examined empirically. Because school leaders have been found to play an important role in school change efforts (Leithwood, Harris \& Strauss, 2010; Supovitz, Sirinides \& May, 2010), it is particularly important to understand the extent to which principals interact with one another in regional learning 
networks. By examining the flow of information and advice in a principals' regional professional learning network and exploring the factors that contribute to interactions between principals, this study serves to build a needed knowledge base.

\section{Theoretical Framework and Research Questions}

The theories of organizational learning (Argyris \& Schön, 1978) and diffusion of innovations (Rogers, 2003) are particularly useful for understanding how network structures can facilitate successful change in that they attend to how information about new ideas moves through and across organizations. For a regional professional learning network to successfully support a shared school change goal, ideas must flow from the school level to the hub as well as between schools, resulting in a "bilateral exchange of knowledge and information" (Peurach et al., 2016, p. 626). Organizational learning theory (Argyris \& Schön, 1978) focuses attention to these critical information exchanges, identifying the presence of feedback loops as necessary for learning to take place at an organization level. Feedback loops are created when localized information about context and implementation challenges, and knowledge/advice regarding how to address those challenges are shared vertically within the organization resulting in new practices which become institutionalized (Argyris \& Schön, 1978). By identifying information and advice exchanges between school leaders and a network's hub organization, we can identify the potential for organizational learning.

However, a regional professional learning network focused on a school change goal must do more than just learn. It must spread innovations in a manner appropriate to the benefits and challenges of the loosely coupled nature of schools. This process can be understood by turning to diffusion theory (Rogers, 2003), which highlights the importance of fit between innovation and localized need. A close fit leads to the early adoption of the innovation. As adoption spreads, it becomes linked with organizational legitimacy, and context fit becomes less important (Rogers, 2003). Diffusion theory highlights the importance of context and adaptations to context. A regional professional learning network, which is made up of members representing a variety of school contexts, has the potential to uncover the specific contexts which are well-suited to successfully implement a reform. Network members from local school contexts which are particularly well fit to the reform goal of focus are likely to be active in information and advice exchanges with the network hub and other members from school sites which share a similar context.

Thus, understanding how information and advice (the building blocks of knowledge) flow within a collaborative school network is important for understanding the network's potential as a catalyst for change within a school and across a region. As more school leaders consider participating in these networks, there is a greater need for more research to understand network effectiveness for supporting school change and how participation may impact the work of school leaders. This study begins to fill this gap by exploring how members of a regional professional learning network for school leaders, referred to here as the Principals Network (PN), interact to share knowledge in support of the shared network goal of implementing personalized, proficiency-based learning in their schools. To guide this inquiry, I explore the following research questions:

1. How does knowledge flow across the Principals Network? 
2. Which personal characteristics of network actors are related to the formation of a network tie?

3. Which school context characteristics are related to the formation of a network tie?

\section{Methods}

Social network analysis (SNA) provides the analytical tools for linking specific behaviors of individuals to social and organizational structures (Carolan, 2014) and is used to examine how information flows through social networks by making interactions between individuals visible (Borgatti \& Ofem, 2010). Thus, this study utilizes SNA as a method of analysis in order to understand how knowledge moves through a professional network.

In SNA, members of a network are called actors. A tie, or interaction, is identified as existing between two actors when one nominates another in response to a question about a particular interaction or relationship, and so a tie is an expression of a specific relation. The collection of ties among all network members is typically called a relational network, but to avoid confusing this with the use of "network" as a descriptor of the Principal's Network (the entity under study) in this paper a collection of relational ties will be referred to as a web. Information and advice are the building blocks of knowledge (Spillane, Healey \& Chong, 2010), thus in this paper, two relational webs - information and advice — are explored.

\section{Research Context}

This study centers on the PN, which is a subnetwork of a much larger network of over 125 secondary schools spanning five states in the northeastern United States. All names in this paper are pseudonyms. I begin by describing the larger network, which provides context for the PN subnetwork. All of the schools involved in the larger network share the goal of implementing personalized, proficiency-based learning. At the time of this study, the larger network had been in existence for six years. The larger network was coordinated by a private non-profit organization which I will refer to as the Learning Collaborative (LC) and which served as the network hub. LC had staff in each state who facilitated network activities including an annual regional network conference, annual state conferences, site visits, and a virtual book club. The LC also coordinated the PN, and thus also served as the PN's hub.

The PN began three years prior to this study and was free to any member of the larger network coordinated by the LC who was a building leader. Initially founded with the support of grant funds, this smaller "principals only" network provided building leaders an opportunity to learn from peers who were also working to implement personalized, proficiency-based learning in their schools. At the time of this study, twenty-five school principals were members of the PN. Members attended three meetings over the course of the academic year and were organized into two groups with assigned facilitators who were staff members of the LC. Facilitators supported discussions at network meetings where members shared their challenges following a facilitated, structured discussion protocol. In these discussion groups members helped one another think through potential solutions to their challenges. 
The PN was selected for study because network members were all school principals. Members represented diverse school contexts in terms of grade levels served, school size, the economic demographics of the student population and state policy contexts. Thus, this entity provided an opportunity to examine of the flow of knowledge and the factors that contribute to tie formation among a diverse group of school leaders in one regional professional learning network.

\section{Participants}

All 25 members of the PN were invited to participate in this study. In total, 20 of the 25 PN members, all principals, completed the survey. Nineteen of the 20 participants responded to questions regarding who they contacted for information or resources and from whom they received advice regarding the implementation of personalized, proficiency-based learning during the current academic year (approximately four months), resulting in a 76\% response rate. All of the participants had at least four years of administrative experience, with $63 \%$ having more than 10 years of experience. The majority of respondents were male $(63 \%)$, and all identified as white, non-Hispanic.

Table 1: Characteristics of survey participants

\begin{tabular}{ll}
\hline Characteristics of Survey Participants & \# of Participants \\
\hline Demographics & \\
\hline Male & 12 \\
\hline Female & 8 \\
\hline White/Non-Hispanic & 20 \\
\hline Administrative Experience (yrs) & \\
\hline 4-6 years & 4 \\
\hline 7-10 years & 4 \\
\hline More than 10 years & 12 \\
\hline Participation in PN (yrs) & \\
\hline Less than 1 year & 5 \\
\hline 1-2 years & 7 \\
\hline More than 2 years & 8 \\
\hline
\end{tabular}

\section{Data Collection}

The hub organization, LC, provided a list of PN members and information about how principals were grouped during facilitated PN meetings. All participant data was collected using an online survey instrument developed through the survey platform, Qualtrics. In an open response format, the survey asked participants to name up to six individuals (name and organization) to whom they reached out for information and/or resources during the past four months. Participants were also asked to rate the frequency of those interactions. In addition, the names and organizational affiliations of up to six people from whom participants received feedback, support and/or guidance (advice) were asked, as was the frequency of those interactions over the same period of time. The survey included participant demographic questions as well as questions about years of experience in various education roles and years of participation in the network. Principals were invited to 
complete the survey at a regularly scheduled network meeting or at their convenience over a twoweek period. Several participants nominated individuals who were not members of the PN as sources of information and/or advice. Personal demographic information on these non-PNmember individuals was not available, however, online state databases enabled the collection of information about school size and population demographics for the schools where these individuals worked, as well as the schools of the participating PN members

Table 2: Characteristics of actors nominated by participants as information and/or advice source

\begin{tabular}{|c|c|}
\hline Characteristic & $\begin{array}{l}\text { \# of Nominated } \\
\text { Actors }\end{array}$ \\
\hline PN member (participant) & 18 \\
\hline Larger network member & 7 \\
\hline Outside of network principal & 2 \\
\hline Consultant & 2 \\
\hline \multirow[t]{2}{*}{ Hub } & 1 \\
\hline & 30 \\
\hline Male & 20 \\
\hline Female & 9 \\
\hline \multirow[t]{2}{*}{$\begin{array}{l}\text { Hub (aggregate of multiple } \\
\text { individuals/gender) }\end{array}$} & 1 \\
\hline & 30 \\
\hline
\end{tabular}

Table 3: School site characteristics of nominated actors

\begin{tabular}{|c|c|}
\hline Characteristic & Mean (Range) \\
\hline School size & $670.45(281-1416)$ \\
\hline $\begin{array}{l}\% \text { of students receiving FRL } \\
\text { benefits }\end{array}$ & $29.71(7.7-76)$ \\
\hline Grades Served & \# of schools \\
\hline Middle school only & 4 \\
\hline High school only & 20 \\
\hline Middle and high school & 3 \\
\hline Total & $27^{*}$ \\
\hline Location & \# of schools \\
\hline State 1 & 9 \\
\hline State 2 & 8 \\
\hline State 3 & 2 \\
\hline State 4 & 8 \\
\hline State 5 & 0 \\
\hline Total & $27 *$ \\
\hline
\end{tabular}

Note. $*$ The hub and two nominated consultants were not affiliated with a specific school site. 


\section{Data Analysis}

SNA methods were utilized to analyze the data using the software program UCINET 6.665 (Borgatti, Everett and Freeman, 2002), which is specifically designed for the analysis of social networks. This process began by assigning identifying codes for each participant member of the PN and for each non-PN member nominated by a PN member as an information or advice tie. Because the network hub (LC) is an established organization with internal mechanisms that support communication among staff, all LC employees nominated as information or advice ties were condensed into one hub actor (one assigned code). An edgelist - a spreadsheet listing each PN member, the contact they listed, the nature of the contact (information or advice), and the frequency of that contact - was then created (Borgatti, Everett and Johnson, 2013). Using UCINET 6.665, this edgelist was converted into two matrices - one for information-seeking interactions and one for advice-receiving interactions. Next, demographic and other descriptive responses were used to create a spreadsheet of member attributes, including gender, role, and number of years of membership in the PN. This attribute spreadsheet also included school context characteristics for each PN member principal, as well as principals nominated as information and/or advice ties who were not PN members. Data included the state in which the school was located, the presence of middle school (5-8) and/or high school (9-12) grade levels, the percentage of the school population that received free and reduced lunch benefits, and the number of students enrolled. This attribute spreadsheet was matched to the matrices using the analytical software package UCINET to allow for the correlation of individual attributes to tie formation (Borgatti, Everett and Johnson, 2013). Visualizations of the reported information-seeking and guidance-receiving interactions were created using NetDraw 2.166 (Borgatti, 2002) and the analytical tools in UCINet 6.665.

\section{Knowledge Flows}

Knowledge is conceptualized as the information and advice exchanged among participants and is measured by the density of interactions in both the information and advice webs in the PN. The presence of network fragments - components of a network disconnected from the information and/or advice exchanges within the core of the network - aids in describing how knowledge flows among the PN members (Borgatti, Everett and Johnson, 2013).

\section{Information Brokers}

Information brokers are individuals who not only have access to much of the knowledge of the PN, but also hold a key position within the network that enables these individuals to exert some control over the knowledge accumulated by the network (Burt, 1992). Such key actors can be identified through various actor centrality measures which quantify an actor's prominence in a social network (Wasserman and Faust, 1994). To determine the individuals who serve as information brokers in the PN, actor centrality was calculated using two different centrality measurement functions in UCINET. First, to identify the most prominent sources of information and advice, degree centrality was calculated for each actor in the information web, and also for each actor in the advice web. This measure of centrality examines the number of incoming (indegree) ties and outgoing (out-degree) ties for each actor in each web (Freeman, 1979; Zemljič \& Hlebec, 2005); therefore, this measure provides information about the relative prominence of 
actors in the network's information and advice exchanges. The in-degree scores of actors in the information web matrix were used to identify those individuals identified most often as information sources in the information web. In-degree scores indicate how many participants nominated an actor as an information source. The actors most often identified as a source of advice were determined by evaluating the in-degree scores of actors in the advice web matrix.

While degree centrality provides insight into popular/important actors for information and advice, this measure only examines direct ties present between actors. A second measure of centrality, flow betweenness centrality (Freeman, Borgatti \& White, 1991; Zemljič \& Hlebec, 2005), considers all ties between all actors and the strength of those ties, and thus is "a measure of the contribution of an actor to all possible maximum flows" (Zemljič \& Hlebec, 2005, 76.). This measure is particularly appropriate for a knowledge network because it quantifies the extent to which the flow of knowledge among the many pairs of actors in the network would be reduced if an identified actor were removed from the network. This measure also acknowledges that information is not limited to moving through the shortest path (Freeman, Borgatti \& White, 1991).

\section{Factors Impacting Tie Formation}

A quadratic assignment procedure (QAP) regression was conducted to test for significant relationships between the strength of a tie between actors, as measured by the frequency of interactions, and actor attributes. Participant interactions in a network are by nature dependent; thus, violate the assumption of independence of observations necessary to run a logistic regression. In a QAP regression, all data (dependent and independent variables) are in matrix form. QAP regression utilizes a procedure whereby the values within the matrix are repeatedly randomly reassigned to generate a p-value for the observations of interest (Borgatti, Everett and Johnson, 2013). Using UCINET, data on the following variables describing attributes of network actors was converted into matrices: years of participation in the PN; assigned PN group; and actor gender. These variables were selected because of a phenomenon called homophily - people are more likely to have ties to others with similar characteristics (Wasserman and Faust, 1994). Gender and length of tenure with the PN are likely to be personal characteristics one principal member might readily identify about another. Another important group of variables relate to the context of the principal's school (Spillane et al, 2015). These included the state in which the school is located; whether the school is a high school (includes grades 9-12); the percentage of students receiving free or reduced lunch benefits; and the size of the student population.

A total of six regression models were run. Three of the models included all nominated actors, regardless of status as a member of the PN. In model 1a, the dependent variable is the strength of both information and advice ties between actors. Each relational web was also analyzed separately, with the dependent variable in model $1 \mathrm{~b}$ being the strength of informational ties, and in model 1c the strength of advice ties. A second set of models included only the official members of the PN and did not include those outside the PN who were nominated as information or advice sources by PN members. However, because the results were similar, but the significance of models and variables was less - likely in part due to the lower number of interactions/observations - only the results of the three models involving all nominated individuals, regardless of PN membership status, are reported. 


\section{Results}

Analysis revealed that the majority of survey respondents were active in the PN. Sixteen of the 19 principals $(84 \%)$ who responded to the survey questions on network activity reported seeking information or receiving advice from others. The majority of the reported interactions were between principals and representatives of the hub organization, with very few PN members reporting no interactions with the network hub. Principals who were members of the larger "parent" network but were not members of the PN were also important sources of information or advice for several PN members. These interactions are visible in Figure 1 (below), which illustrates the information and advice interactions reported by the participating PN principals. In social network visualizations, each shape is called a node and, in this image, represents an individual who was either a member of the PN or was nominated by a member of the PN as a source of information or advice. A reported interaction (either seeking information and/or receiving advice) is represented by an arrow. The arrowhead indicates the direction of the interaction. Notice that the majority of PN principals, represented by single letters A-T, identified the hub (X) as a source of information and/or advice. Below, I address the findings for each research question.

Figure 1: Complete web of knowledge flows (information and advice combined)

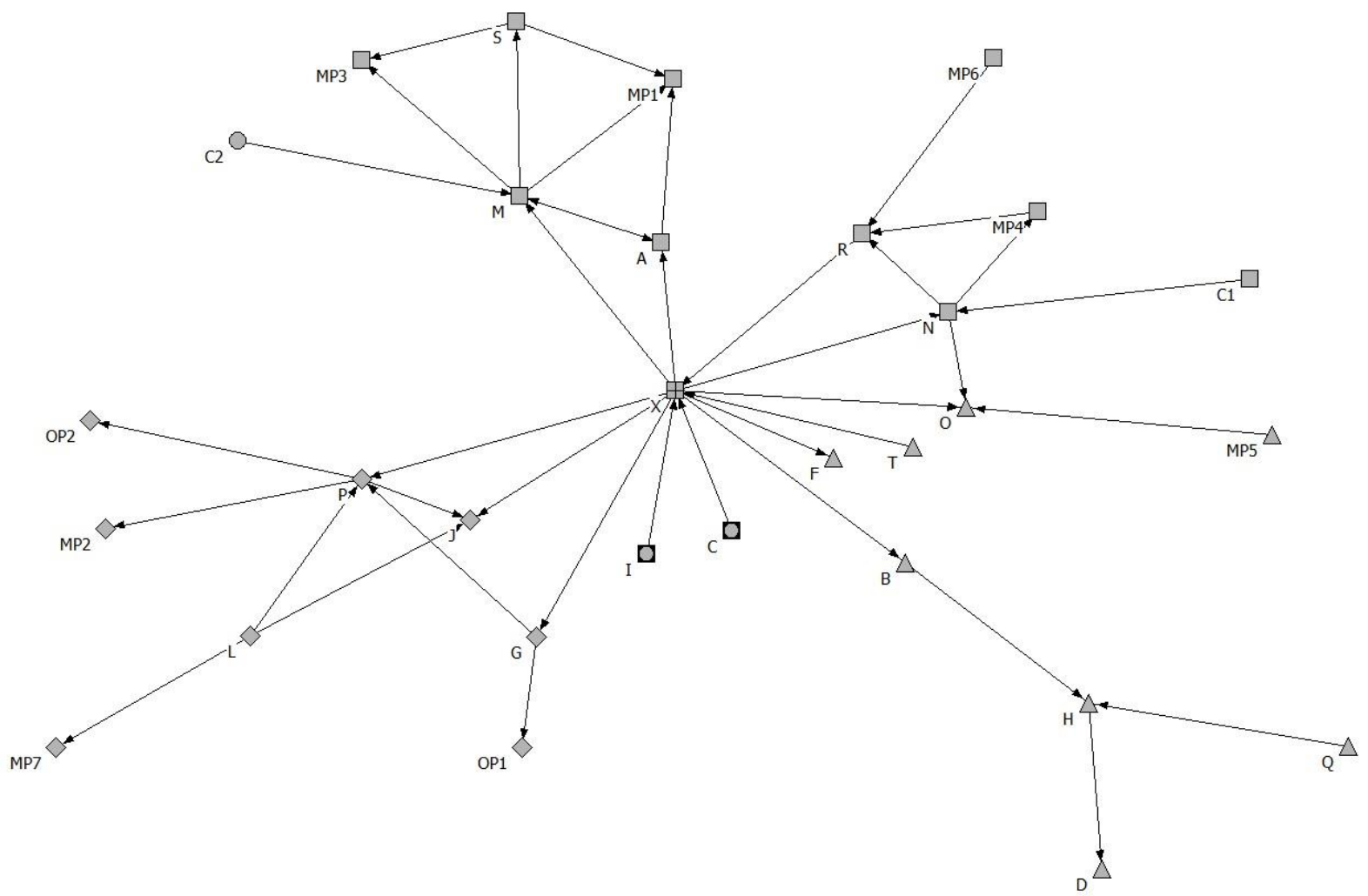

Note. Node shapes depict state affiliations with the hub node $(\mathrm{X})$ having representation in multiple states. 


\section{Knowledge Flows across the PN}

The first research question asks how knowledge flows across the PN. Again, knowledge flows are conceptualized as the combined webs of information and advice ties. Overall, there were few ties between network members compared to the total number of possible ties that could exist. The majority of people involved in the PN were connected to others by only one tie. However, participants described these interactions as "frequent" only slightly less often than "occasional". Very few respondents reported one-time interactions, indicating that emerging as well as established relationships were present between individuals. The sections below examine the information and advice webs separately.

\section{Information Flows}

Overall, PN members reported significantly more information-seeking interactions than advicereceiving interactions. In figure 2 (below) the arrow indicates who sought advice from whom. For example, R sought advice from $\mathrm{X}$, while $\mathrm{N}$ sought advice from $\mathrm{R}, \mathrm{X}, \mathrm{MP} 4$ and $\mathrm{C} 1$. Forty-seven percent of PN principals responding to the survey only reported seeking information (they did not report receiving feedback, support or guidance). Figure 2 reveals two isolates, or participants who did not report turning to anyone for information ( $\mathrm{O}$ and $\mathrm{F}$ ). Other isolates (MP5, MP6 and C2) appear in the visualization because they were nominated by participants as a source of advice, however they were not participants in this study. In addition to isolates, there were two fragments within this relational web. Network fragments are subgroups of individuals who turned to one another for information, but did not look to LC staff, nor did they report interactions with any other individuals who reported reaching out to LC staff for information. As such, the information web is not a fully connected network. Individuals who reported reaching out for information were most likely to reach out to other principals rather than LC staff. 
Figure 2: Information-seeking interactions reported by participants

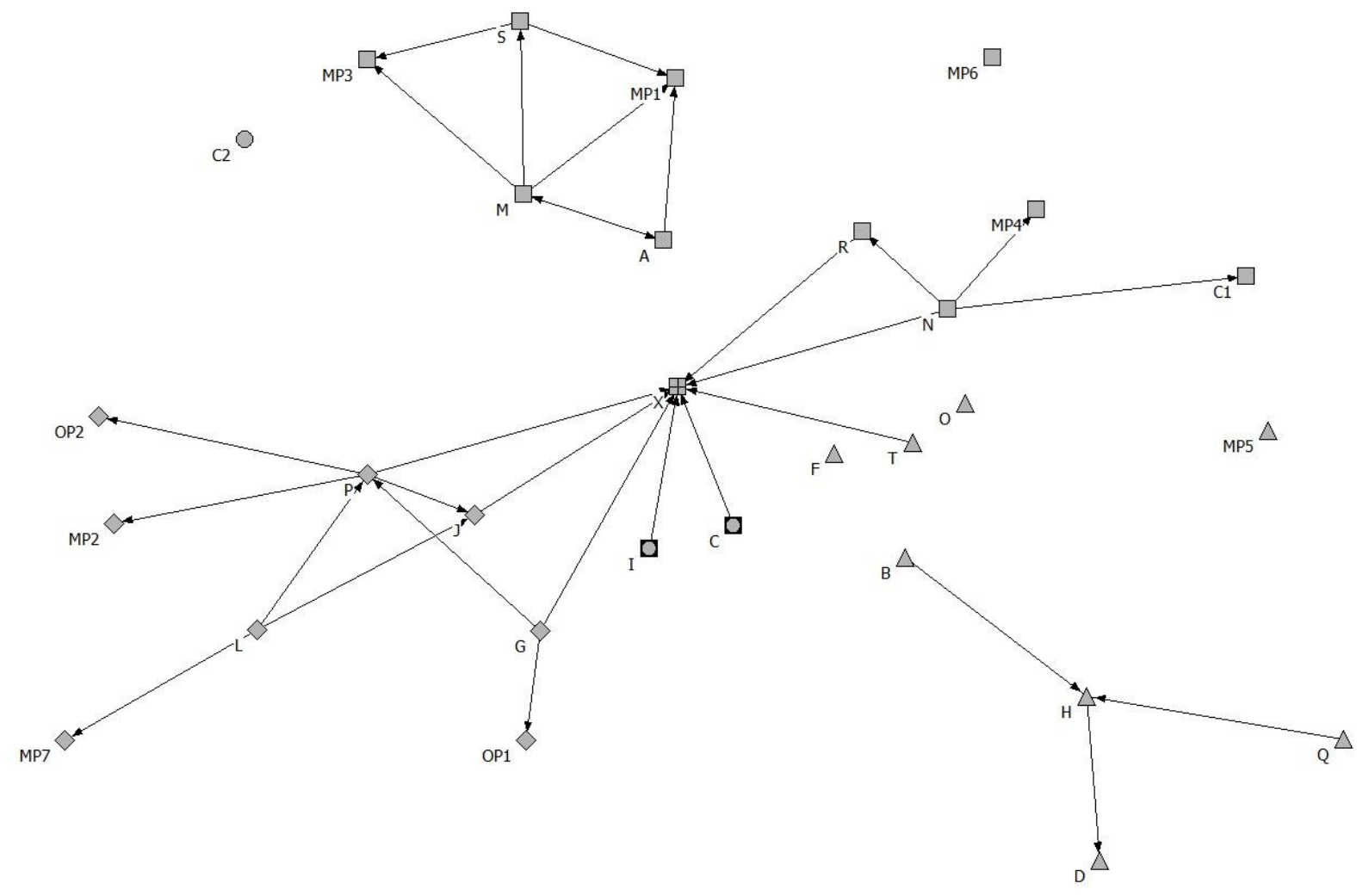

Note. Node shapes depict state affiliations with the hub node $(\mathrm{X})$ having representation in multiple states.

\section{Advice Flows}

The LC staff were particularly important to the advice (feedback, support and guidance) interactions reported in the network. In figure 3 (below) the arrow indicates from whom a participant reported receiving advice. For example, $\mathrm{N}$ reported receiving advice from $\mathrm{X}$ and $\mathrm{C} 1$, while $\mathrm{R}$ and $\mathrm{O}$ reported receiving advice from $\mathrm{N}$. All but one of the $\mathrm{PN}$ members receiving advice identified the LC as a source of that support, and nine of the $16(56 \%)$ reported advice ties were to LC staff. Principals who were members of the greater network, but not members of the PN, were another important source of advice regarding personalized, proficiency-based learning (MP4, MP5 and MP6). There were only two direct advice ties between member principals and two ties to outside consultants ( $\mathrm{C} 1$ and $\mathrm{C} 2)$. Overall, PN members reported fewer advice-receiving ties as compared to information/resource seeking ties. Nine of the 19 principal members (47\%) did not report any advice interactions. In figure 3 we see many isolates, individuals who are not participating in advice interactions. However, in contrast to the web of information ties-which contained two disconnected network fragments - the web of advice ties has no fragments. 
Figure 3: Advice-receiving interactions reported by participants

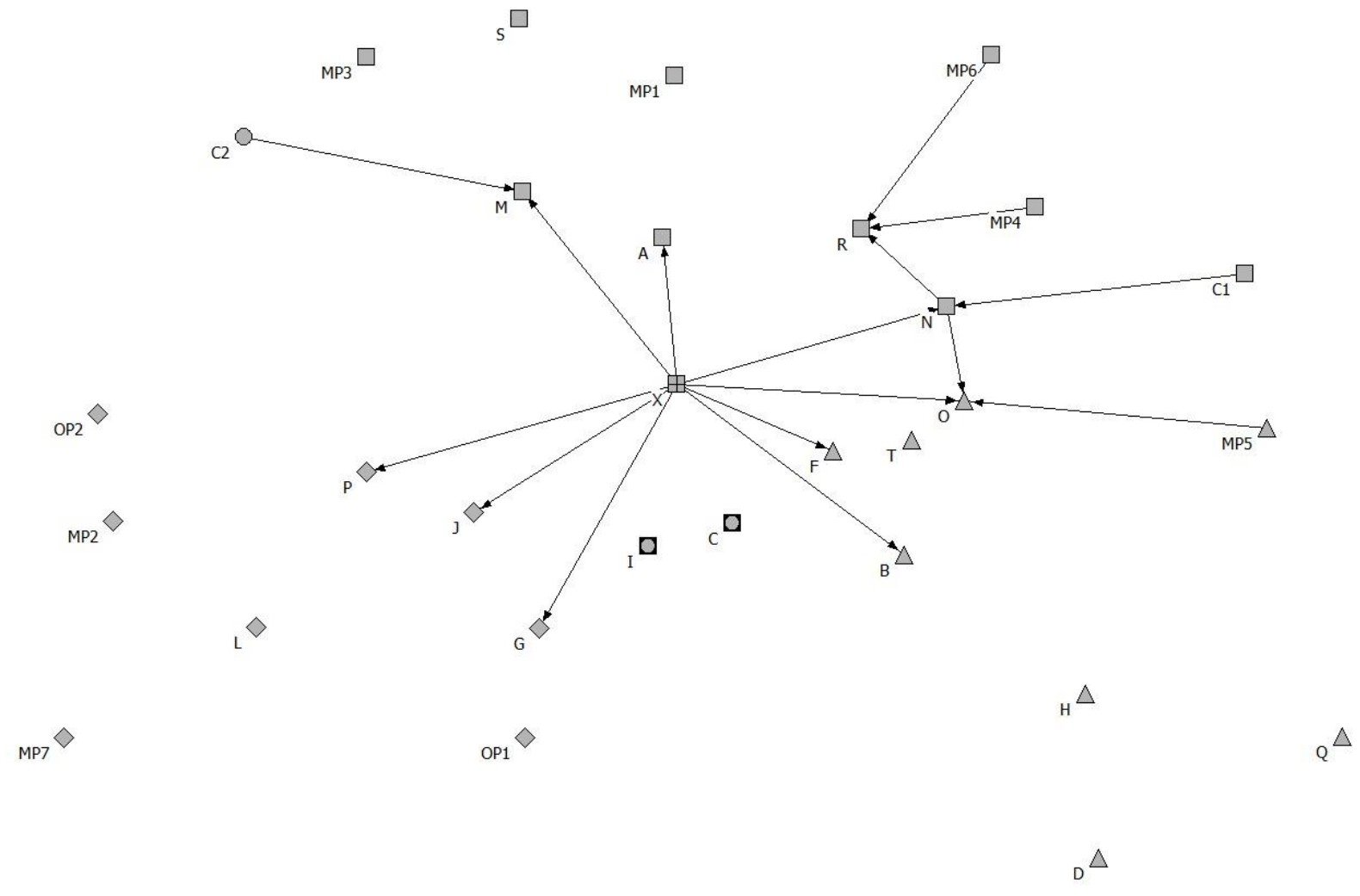

Note. Node shapes depict state affiliations with the hub node $(\mathrm{X})$ having representation in multiple states.

\section{Information Brokers}

Based on their position within the network knowledge flows, some individuals were more likely to be important resources for information and advice than others, and therefore can be described as information brokers (Burt, 1992). These network actors may have exerted more influence over others in the network due to their popularity as information and/or advice sources. Because they served to connect subgroups that might otherwise have been disconnected from the rest of the network, these individuals were also positioned to control the information that others received. In these respects, information brokers play a central role in facilitating the flow of knowledge across a network (Burt, 1992). Centrality scores are useful for comparing the status of actors in relation to others within the same relational web. However, they are not normalized for comparisons across different relational webs. Examinations of actor centrality revealed that the hub (X) received a centrality score significantly higher than any other actor in the information and advice web degree centrality calculations, as well as in the measures of flow betweenness (see Table 4 below). 
Table 4: Central actors by centrality measure

\begin{tabular}{ll|ll|ll}
\hline $\begin{array}{l}\text { Degree Centrality- } \\
\text { Information Web }\end{array}$ & \multicolumn{2}{|l|}{$\begin{array}{l}\text { Degree Centrality- } \\
\text { Advice Web }\end{array}$} & \multicolumn{2}{l}{$\begin{array}{l}\text { Flow Betweenness Centrality- } \\
\text { Combined Webs }\end{array}$} \\
\hline Actor & $\begin{array}{l}\text { In- } \\
\text { Degree }\end{array}$ & Actor & $\begin{array}{l}\text { In- } \\
\text { Degree }\end{array}$ & Actor & Flow Capacity \\
$\mathrm{X}$ & 20 & $\mathrm{X}$ & 22 & $\mathrm{X}$ & 140.50 \\
\hline $\mathrm{MP1}$ & 6 & $\mathrm{~N}$ & 4 & $\mathrm{R}$ & 69.50 \\
\hline $\mathrm{J}$ & 5 & $\mathrm{C} 1$ & 3 & $\mathrm{~N}$ & 29.50 \\
\hline MP3 & 4 & $\mathrm{C} 2$ & 3 & $\mathrm{M}$ & 25.50 \\
\hline \multicolumn{7}{l}{ Note. Only the top four scores are reported } \\
\hline
\end{tabular}

Prominent actors in the information web. While the hub also dominated the information web with an in-degree score of 20 , a different set of secondary actors were identified as important in the information web. Here two principals who were not members of the PN, but were affiliated with the PN's parent network, were among the top four actors. These were MP1 and MP3 with scores of 6 and 4 respectively. One PN member principal, J, was also among the top four with a score of 5. These central actors can be seen in figure 2 .

Prominent actors in the advice web. The examination of degree centrality in the advice web indicated that the hub received a score of 22. This is quite high considering the next highest score was 4 , earned by PN member N, who was the only principal among the top 4 scores, and indicates that the hub was by far the most utilized, and therefore important source of advice in the PN. The other top scores were attributed to the outside consultants, $\mathrm{C} 1$ and $\mathrm{C} 2$, who both received a score of 3 . These central actors can be seen in figure 3 .

Actors important to the flow of information across the combined webs (knowledge network). The analysis of flow betweenness centrality in the combined information and advice webs revealed once again that the hub holds a place of high importance to the flow of information across the network with a value of 140.50 . The range of scores was $0.00-140.50$, with a mean of 11.03 and standard deviation of 28.02. The next three most valuable actors to the flow of information were PN principals R (69.50), N (29.50) and M (25.50). This can be seen in figure 1. An examination of the demographic information and work experience collected reveals that these prominent actors did not share common characteristics. They were male and female and varied in their experience with the PN and their work experience.

\section{Contribution of Personal and Context Characteristics to Network Ties}

The QAP regression results provided answers to the second and third research questions, which asked about the personal and context characteristics that contributed to the formation of an information and/or advice tie within the PN. The models began with a set of variables describing characteristics of individual network actors - same gender (Gender), same number of years in the PN (Yrs PN) - as well as a set of variables describing the school context of each network actorsame state (State), both serving high school students $(H S)$, absolute difference in size of student 
population (Size), absolute difference in percentage of students receiving free or reduced lunch (FRL).

\section{Combined Information and Advice Relationships}

The following model was found to be significant in explaining the strength of combined information and advice ties for all nominated actors and demonstrated the best fit with an adjusted $\mathrm{R}$ value of .01103 and a $\mathrm{p}$ value of .001:

$\mathrm{Y}=-.00979-.02189($ Yrs PN) $* *+.03915($ State $) * *+.01237($ HS $)+.00003($ Size $)$

This model indicates a statistically significant negative relationship $(\mathrm{p}<.05)$ between the strength of the information and advice ties between actors (as measured by frequency of reported interactions over a four month period) and the two actors being in the PN for the same number of years, holding all other independent variables constant. This means that a tie is more likely to form if individuals did not join the PN in the same year. Being in the same state was also significant (p $<.05)$ and was positively correlated with the strength of relationship. Strength of tie was also positively correlated when both actors served high school students and when their student populations were of similar sizes. These last two variables increased the explanatory power of the model and aided in the model's overall significance, however, they were not statistically significant.

\section{Advice Relationships}

The model explaining the strength of advice ties was similar to the model for both relationships combined, with one additional personal characteristic contributing to the explanatory power of the model. The final model explaining the strength of advice ties had an adjusted $\mathrm{R}^{2}$ of .01046 and a $\mathrm{p}$ value of .0040 .

$\mathrm{Y}=-.0052-.00982($ Gender$)-.02242($ Yrs PN) $* *+.03885($ State $) * * *+.01288(\mathrm{HS})+.00003$ (Size)

Here the context characteristic of same state had a positive and highly significant impact on the strength of a tie $(\mathrm{p}<.01)$, while both personal characteristics - same number of years in the PN ( $\mathrm{p}$ $<.01$ ) and same gender (not statistically significant) — had a negative impact. Holding all other independent variables constant, an advice relationship is likely to be weaker if both individuals have been in the PN for the same number of years. This result is surprising considering the importance of homophily for tie formation in social network theory (Wasserman and Faust, 1994).

\section{Information Relationships}

When examining information ties only, none of the variables related to characteristics of individual actors were found to be significant or contribute to the overall model in a meaningful way. However, being in the same state had a highly significant and positive effect $(\mathrm{p}<.001)$. Also significant were both actors serving high school students $(\mathrm{p}<.05)$ and having similarly sized student populations $(\mathrm{p}<.1)$. Contributing to the model was having similar percentages of students receiving free and reduced lunch benefits, though this variable was not significant. The final model 
for explaining the strength of information ties for all nominated actors had an adjusted $\mathrm{R}$ value of .08439 and a $\mathrm{p}$ value of .00050 .

$\mathrm{Y}=.00383+.21516($ State $) * * *+.06269(\mathrm{HS}) * *-.00083(\mathrm{FRL})-.00009(\text { Size })^{*}$

Table 5: QAP Regression Results

\begin{tabular}{|c|c|c|c|c|c|}
\hline & $\beta$ & SE & $\mathbf{R}^{2}$ & $\operatorname{Adj} R^{2}$ & $\mathbf{P}$ \\
\hline Combined info and advice relationships & & & .0167 & .011 & .001 \\
\hline Same \# years in PN (Yrs PN) & $-.02189 * *$ & .01452 & & & \\
\hline Same state (State) & $.03915 * *$ & .01429 & & & \\
\hline Both serve high school (HS) & .01257 & .01716 & & & \\
\hline Absolute difference of school size (Size) & .00003 & .00003 & & & \\
\hline Advice relationships & & & .0175 & .0105 & .004 \\
\hline Same gender (Gender) & -.00982 & .01345 & & & \\
\hline Same \# years in PN (Yrs PN) & $-.02242 * *$ & .01492 & & & \\
\hline Same state (State) & $.03885 * * *$ & .01437 & & & \\
\hline Both serve high school (HS) & .01299 & .01738 & & & \\
\hline Absolute difference of school size (Size) & .00003 & .00003 & & & \\
\hline Information relationships & & & .0896 & .0844 & .0005 \\
\hline Same state (State) & $.21516 * * *$ & .03204 & & & \\
\hline Both serve high school (HS) & $.06269 * *$ & .03516 & & & \\
\hline $\begin{array}{l}\text { Absolute difference of FRL population } \\
\text { (FRL) }\end{array}$ & -.00083 & .00097 & & & \\
\hline Absolute difference of school size (Size) & $-.00009 *$ & .00006 & & & \\
\hline
\end{tabular}

\section{Discussion}

\section{Knowledge Flows across the PN}

In response to the first research question, which asked about the flow of knowledge among members of the $\mathrm{PN}$, results of the analysis of information-seeking and advice-receiving interactions revealed that the network hub, the LC, was important to the flow of knowledge across the PN. Knowledge flowed from the hub to principals and also from principals to the hub creating the feedback loops necessary for organizational learning (Argyris \& Schön, 1978; Peurach, 2016). The LC was the most prominent actor across all actor centrality measures-degree centrality in the advice and information webs. Most members had direct contact with the LC, either through information or advice interactions, allowing for the dissemination of new knowledge gained. In addition, flow betweenness centrality in the two webs combined, which represent overall knowledge flow, revealed that the hub made the largest contribution of all network actors to the movement of knowledge across the network. This supports the literature describing the value of a hub organization for the gathering, documenting and sharing of knowledge gained through the network (Bryk, et. al, 2015; Glazer \& Peurach, 2012; Peurach, et al., 2016) and supports findings by Wohlstetter and colleagues (2003) that the implementation of a context-specific reform may be 
better supported by a hub organization, which is external to the participating school organizations, than by a district's central office staff.

However, the analysis also revealed some potential obstacles to member access to network knowledge. The level of connectedness between network members is likely to influence the network's effectiveness in realizing desired outcomes (Daly, et al., 2014; Liou \& Daly, 2016). Overall, the PN exhibited a low density of network ties, and there were two network fragments, or groups of network actors that did not connect to the central web of information interactions. It was beyond the scope of this study to examine why the network is fragmented and not densely connected. However, in the context of this relatively new regional network that spans not only district, but also state boundaries, the low density of interactions may be evidence of an emerging network rather than of a poorly functioning network. Further research is needed to understand how regional learning networks change over time and how geographic, political and organizational boundaries may impact ties among members.

While the LC was central to the flow of knowledge for organizational learning and the diffusion of innovations, results of the actor centrality analysis among the two relational webs indicated that half of the four most central actors in the webs of information and also advice interactions are not PN network members. In the information web, $\mathrm{C} 1$ and $\mathrm{C} 2$ are outside consultants, while in the advice web, MP1 and MP3 are school principals who are members of the greater network, but not the PN. These central actors have close ties to several PN principals, but have only indirect ties with the network hub. Thus, they are positioned to compete with the hub as information and advice sources. Depending on how well aligned these sources are with the overall network's ideals and values relating to the implementation of network goals, the strong positions of these outside actors may be problematic for network knowledge-building and goal implementation. More research examining regional professional learning networks is needed to better understand how the involvement of external individuals may impact knowledge-building and dissemination.

Another concern is the number of principals who reported no interactions. When principals do not participate in information flows, it is difficult for networks to have an impact at the school level (Finnigan, Daly \& Che, 2013). This may be related to the critical role principals play as communication links between the network and the school (Liou \& Daly, 2016).

\section{Personal Characteristics Contributing to Strength of Ties}

The second research question asked, "which personal characteristics of network actors are related to the formation of a network tie?" According to social network theory, ties are more likely to form among individuals with similar characteristics (Wasserman \& Faust, 1994). Thus, one would expect a positive relationship between the degree of similarity of actors (same number of years in the network or same gender) and the strength of tie between these actors. However, among PN interactions, gender had no statistically significant impact, while number of years with the PN had no impact on information interactions and a statistically significant negative impact on advice interactions, indicating that principals may be reluctant to receive advice from those who they perceive to have a similar level of experience with the implementation of personalized, proficiency-based learning. The findings of a negative impact of experience with the PN on advice 
interactions may be explained by findings from a study by Daly and colleagues (2014) which revealed that advice-seeking behavior among principals tended to happen more outside of one's area of expertise. Principals may view those of the same cohort as having similar levels of expertise in regard to personalized, proficiency-based learning, and thus look outside of their cohort for advice.

Another explanation may be that the structure of network meetings and facilitated events shaped opportunities for interaction, and therefore encouraged tie formations that would not likely have occurred naturally. Individuals with different levels of experience or different genders may have been (intentionally or unintentionally) encouraged to participate in facilitated discussions and network events in different ways, resulting in the reported ties. More research investigating the effects of facilitation practices and meeting structures on information and advice ties is needed to explore this finding of a negative relationship between similarity of number of years of membership and the strength of advice ties in a regional professional learning network.

\section{Impact of School Context Characteristics}

In contrast to the personal characteristics of actors, several school context characteristics were important to the strength of information ties within the information web. This is noteworthy because the information-seeking web was not only denser than the advice-receiving web, it also had fewer ties involving the network hub; thus, had more observations to contribute to the QAP analysis. Here, being in the same state had a large and highly significant ( $p<.001)$ positive impact on strength of tie. This is corroborated by the visualization of this network (Figure 2), which reveals two information subgroups made up exclusively of actors from the same state. Research into the diffusion of innovations in schools points to the importance of context for the implementation of reforms (Frank, et al., 2010; Rogers, 2003). State boundaries represent distinct political, cultural, demographic and geographic contexts. Therefore, it makes sense that school principals working to implement personalized, proficiency-based learning would seek out information and advice from others facing similar challenges relating to education policy, which often varies across states. Serving a similar student age demographic was also significant in the strength of information relationships. Thus, this study aligned with findings by Spillane and colleagues (2015) indicating that school site characteristics are important in explaining ties between educators in different schools.

\section{Implications and Conclusions}

While the information presented in this study illuminates the knowledge flows and interactions among members of a regional professional learning network for principals, there are important limitations to note. First, only principals who were members of the PN participated in the survey. Some actors who were nominated by participating principals as sources of information and/or advice were not members of the PN, and therefore information regarding the work experience and demographic data on these individuals was not available for analysis. This information could have added to our understanding of the personal characteristics that may contribute to tie strength. Second, participants completed this survey in January, at the beginning of their second meeting of the year. The information captured what members recalled regarding their interactions over the 
prior 4 months, but some may not have recalled the names of other members or specific interactions, even if those interactions had yielded valuable information and/or advice. Third, members may have had different interpretations of what constitutes an interaction. Some may have included the facilitated conversations around problems of practice that occurred at PN meetings, while others may have focused on interactions outside of network events. As a result, the information on network interactions may not be complete or consistently defined across participants.

Three important findings with implications for the hub organization come from this study. First, while the LC was highly central in the flow of knowledge across the network, outside consultants and non-member principals were found to be important to both the information and advice webs of interactions. Thus, it may be important for the LC to engage with non-network actors who PN members nominate as important sources of information, in order to better leverage these resources and ensure that the information shared does not conflict with or impede network goals. Second, it appears that site context factors are important to the strength of ties between members. This finding could have implications for how future network participants are selected and/or grouped. Other organizations looking to establish or grow regional professional learning networks should consider the importance of similarities in school site context for the development of ties between network members. In the case of networks spanning political boundaries, there is value in paying extra attention to the cultivation of ties among members who share a similar policy context. Finally, this study brings to light that ties are more likely to form between members who have differing years of experience in the network. This was unexpected and has implications for how the hub organization might structure network events to facilitate interactions between members and foster the formation of strong ties. This also points to the value of bringing in new members over time. Further investigation is needed to better place these findings within a context of other research on regional professional learning networks.

\section{References}

Argyris, C., \& Schon, D. (1978). Organizational learning: A theory of action perspective. Reading, MA: AddisonWesley Publishing Company.

Borgatti, S. P. (2002). NetDraw: Graph visualization software. Harvard, MA: Analytic Technologies.

Borgatti, S. P., Everett, M.G., \& Freeman, L.C. (2002). Ucinet 6 for Windows: Software for social network analysis. Harvard, MA: Analytic Technologies.

Borgatti, S. P., Everett, M. G., \& Johnson, J. C. (2013). Analyzing Social Networks, Sage Publications, London.

Borgatti, S. P., \& Ofem, B. (2010). Social network theory and analysis. In A. J. Daly (Ed.), Social Network Theory and Educational Change (pp. 17-29). Cambridge, MA: Harvard Education Press.

Bryk, A. S., Gomez, L. M., Grunow, A., \& LeMahieu, P. G. (2015), Learning to Improve. Cambridge, MA: Harvard Education Press.

Burt, R. S. (1992). Structural holes: The social structure of competition. Cambridge, MA: Harvard University Press.

Carolan, B. V. (2014). Social Network Analysis and Education. Thousand Oaks, CA: Sage Publications Inc.

Coburn, C. E., Mata, W. S., \& Choi, L. (2013). The embeddedness of teachers' social networks: Evidence from a study of mathematics reform. Sociology of Education, 86(4), 311-342.

Daly, A. J., \& Finnigan, K. S. (2012). Exploring the space between social networks, trust, and urban school district leaders. Journal of School Leadership, 22, 493-530.

Daly, A. J., Finnigan, K. S., Moolenaar, N. M., \& Che, J. (2014). The critical role of brokers in the access and sse of evidence at the school and district level. In A. J. Daly (Ed.), Using Research Evidence in Education (pp. 1331). New York, NY: Springer International Publishing. 
Daly, A. J., Moolenaar, N. M., Bolivar, J. M., \& Burke, P. (2010). Relationships in reform: The role of teachers' social networks. Journal of Educational Administration, 48(3), 359-391.

Dekker, D., Krackhardt, D., \& Snijders, T. (2003). Multicollinearity robust QAP for multiple-regression, presented at the NAACSOS conference, Omni William Penn, Pittsburgh, PA, 1-5.

Finnigan, K. S., Daly, A. J., \& Che, J. (2013). Systemwide reform in districts under pressure. Journal of Educational Administration, 51(4), 476-497.

Frank, K. A., Penuel, W. R., \& Krause, A. (2015). What is a "good" social network for policy implementation? The flow of know-how for organizational change. Journal of Policy Analysis and Management, 4(2), 378-402.

Frank, K. A., Zhao, Y., Penuel, W. R., Ellefson, N., \& Porter, S. (2011). Focus, fiddle, and friends, Sociology of Education, 84(2), 137-156.

Freeman, L. C., Borgatti, S. P., \& White, D. R. (1991). Centrality in valued graphs: A measure of betweenness based on network flow. Social Networks, 13, 141-154.

Fullan, M. (2011). Choosing the wrong drivers for whole system reform. In Seminar Series 204. East Melbourne: Centre for Strategic Education.

Glazer, J. L., \& Peurach, D. J. (2012). School improvement networks as a strategy for large-scale education reform: The role of educational environments. Educational Policy, 27(4), 676-710.

Leithwood, K., \& Azah, V. N. (2016). Characteristics of effective leadership networks. Journal of Educational Administration, 54(4) 409-433.

Leithwood, K., Harris, A., \& Strauss, T. (2010). Leading school turnaround. San Francisco, CA: Jossey-Bass.

LeMahieu, P. G., Grunow, A., Baker, L., Nordstrum, L. E., \& Gomez, L. M. (2017). Networked improvement communities. Quality Assurance in Education, 25(1), 5-25.

Levin, B., \& Fullan, M. (2008). Learning about System Renewal. Educational Management Administration \& Leadership, 36(2), 289-303.

Liou, Y. H., \& Daly, A. J. (2016). Diffusion of innovation: A social network and organizational learning approach to governance of a districtwide leadership team. Pedagogia Social Revista Interuniversitaria, 28, 41-55.

Moolenaar, N. M., \& Sleegers, P. (2010). Social networks, trust, and innovation: The role of relationships in supporting an innovative climate in Dutch schools. In A. J. Daly (Ed.), Social Network Theory and Educational Change (pp. 97-114). Cambridge, MA: Harvard Education Press.

Moolenaar, N. M., \& Sleegers, P. (2015). The networked principal: Examining principals' social relationships. Journal of Educational Administration, 53(1), 8-39.

Moolenaar, N. M., Sleegers, P., Karsten, S., \& Daly, A. J. (2012). The social fabric of elementary schools: A network typology of social interaction among teachers. Educational Studies, 38(4), 355-371.

Penuel, W. R., Riel, M., Joshi, A., Pearlman, L., Kim, C. M., \& Frank, K. A. (2010). The alignment of the informal and formal organizational supports for reform: Implications for improving teaching in schools. Educational Administration Quarterly, 46(1), 57-95.

Peurach, D. J. (2016). Innovating at the nexus of impact and improvement: Leading educational improvement networks. Educational Researcher, 45(7), 421-429.

Peurach, D. J., Glazer, J. L., \& Winchell Lenhoff, S. (2016). The developmental evaluation of school improvement networks. Educational Policy, 30(4), 606-648.

Peurach, D. J., \& Gumus, E. (2011). Executive leadership in school improvement networks: A conceptual framework and agenda for research. Current Issues in Education, 14(3).

Proger, A. R., Bhatt, M. P., Cirks, V., \& Gurke, D. (2017). Establishing and sustaining networked improvement communities: Lessons from Michigan and Minnesota (REL 2017-264). Washington, DC. Retrieved September 20, 2018 from http://files.eric.ed.gov/fulltext/ED573419.pdf

Robins, G. (2015). Doing Social Network Research. London: Sage Publications.

Rogers, E. M. (2003). Diffusion of Innovations. (5th ed.). New York, NY: Free Press.

Russell, J. L., Bryk, A. S., Dolle, J., Gomez, L. M., LeMahieu, P. G., \& Grunow, A. (2015). A framework for the initiation of networked improvement communities Jennifer. Teachers College Record, 113(12), 2897-2921.

Siciliano, M. D., Moolenaar, N. M., Daly, A. J., \& Liou, Y. H. (2017). A cognitive perspective on policy implementation: Reform beliefs, sensemaking, and social networks. Public Administration Review, 77(6), 889-901.

Spillane, J. P., Healey, K., \& Kim, C. M. (2010). Leading and managing instruction: Formal and informal aspects of the elementary school organization. In A. J. Daly (Ed.), Social Network Theory and Educational Change (pp. 129-158). Cambridge, MA: Harvard Education Press.

Spillane, J. P., Hopkins, M., \& Sweet, T. M. (2015). Intra- and interschool interactions about instruction: Exploring the conditions for social capital development. American Journal of Education, 122(1), 71-110. 

network

Supovitz, J., Sirinides, P., \& May, H. (2010). How principals and peers influence teaching and learning. Education Administration Quarterly, 46(1), 31-56.

Wasserman, S., \& Faust, K. (1994), Social Network Analysis. New York, NY: Cambridge University Press.

Wohlstetter, P., Malloy, C. L., Chau, D., \& Polhemus, J. L. (2003). Improving schools through networks: A new approach to urban school reform. Educational Policy, 17(4), 399-430.

Zemljič, B., \& Hlebec, V. (2005). Reliability of measures of centrality and prominence. Social Networks, 27, 73-88. 